\title{
Application of new tool material for electrical discharge machining (EDM)
}

\author{
A K KHANRA*, L C PATHAK ${ }^{\dagger}$ and M M GODKHINDI \\ Department of Metallurgical and Materials Engineering, National Institute of Technology, Warangal 506004 , \\ India \\ ${ }^{\dagger}$ MST Division, National Metallurgical Laboratory, Jamshedpur 831 007, India
}

MS received 8 July 2007; revised 25 April 2009

\begin{abstract}
In EDM, $\mathrm{Cu}$ and graphite are commonly used as tool materials. The poor wear resistance is the drawback of these tools. In the current study, an attempt has been made to develop a $\mathrm{ZrB}_{2}-\mathrm{Cu}$ composite as an EDM tool material to overcome this problem. Initially, the $\mathrm{ZrB}_{2}$ powder is prepared by self-propagating high-temperature synthesis (SHS) technique and synthesized powder is mixed with different amounts of $\mathrm{Cu}$ powder. Dense composite is developed by a pressureless sintering at $1250^{\circ} \mathrm{C}$. The composites are tested as tool material at different EDM process parameters during machining of mild steel. The $\mathrm{ZrB}_{2}-\mathbf{4 0}$ wt\% $\mathrm{Cu}$ composite shows highest metal removal rate (MRR) with significant tool removal rate (TRR) than other composites. The performance of $\mathrm{ZrB}_{2}-40 \mathrm{wt} \% \mathrm{Cu}$ composite is compared to conventional $\mathrm{Cu}$ tool. The composite shows higher MRR with less TRR than $\mathrm{Cu}$ tool but it shows more average surface roughness and diameteral overcut than $\mathrm{Cu}$ tool.
\end{abstract}

Keywords. EDM; SHS; sintering; composite; metal removal rate; surface roughness.

\section{Introduction}

The EDM is one of the most widely applied nontraditional machining processes for manufacturing of dies in forging/extrusion industries. Material with high hardness and high strength such as super alloys, composites, advanced ceramics etc with close precision and surface finish can be done by EDM satisfactorily, where the traditional machining fails (Petrofes 1988; Gadalla et al 1991; Ho and Newman 2003; Khanra and Khanta 2005; Khanra et al 2006). In EDM, the tool and the workpiece (WP) are connected to two electrodes and separated by a dielectric fluid. High voltage induces a plasma channel between two conductive electrodes and generates a temperature of $\sim 20,000^{\circ} \mathrm{C}$ (Norasetthekul et al 1999). At this condition localized evaporation of electrodes takes place in the plasma channel. Material removal is dependent on several parameters like applied current, pulse duration, gap voltage, frequency of discharge, type of electrode and work material, dielectric flushing condition etc. Basic requirement of EDM tool is the combination of high electrical and thermal conductivity, high melting point and high wear resistance. Commonly, $\mathrm{Cu}$ and graphite tools are used as tool material which has low wear resistance and these tools are not suitable for prolonged machining.

*Author for correspondence (asit_iitkgp@yahoo.com)
Research is going on to develop a composite material which satisfies the basic requirement of tool properties. Few composites tools like $\mathrm{Cu}-\mathrm{W}, \mathrm{Cu}-\mathrm{WC}, \mathrm{Cu}-\mathrm{Cr}$, $\mathrm{Cu}-\mathrm{ZrB}_{2}$ etc have been tested as tool material for EDM study (Samuel and Philip 1997; Norasetthekul et al 1999; Marafona and Wykes 2000; Tsai et al 2003; Singh et al 2004). It has been observed that the $\mathrm{Cu}-\mathrm{W}$ and $\mathrm{Cu}-\mathrm{WC}$ composites tools show poor performance than $\mathrm{Cu}$ tool. The wear resistance of machined surface is improved by using $\mathrm{Cu}-\mathrm{W}$ and $\mathrm{Cu}-\mathrm{WC}$ electrodes. Tsai et al (2003) observed higher MRR than $\mathrm{Cu}$ tool during EDM while using the $\mathrm{Cu}-\mathrm{Cr}$ composite tool. Norasetthekul et al (1999) have tried to develop $\mathrm{ZrB}_{2}-\mathrm{Cu}$ composite by infiltration technique and this composite shows higher MRR with lower TRR than $\mathrm{Cu}$ and graphite tool (Norasetthekul et al 1999). The infiltration technique is a costly process. The manufacturing industries need some composite tool, which can be produced by a cheap process such as pressureless sintering etc.

In the present investigation, an attempt has been made to develop a $\mathrm{ZrB}_{2}-\mathrm{Cu}$ composite by pressureless sintering technique for EDM tool. Initially the $\mathrm{ZrB}_{2}$ (hard ceramic material) is produced by SHS technique and dense composite is prepared by pressureless sintering of $\mathrm{ZrB}_{2}$ with addition of different amounts of $\mathrm{Cu}$. The EDM study is carried out with $\mathrm{ZrB}_{2}-\mathrm{Cu}$ composite as tool materials at different EDM process parameters during machining of mild steel. 


\section{Experimental}

The $\mathrm{ZrB}_{2}$ powder was produced by igniting the stoichiometric mixture of $\mathrm{H}_{3} \mathrm{BO}_{3}, \mathrm{ZrO}_{2}$ and $\mathrm{Mg}$ in an inert chamber. After the combustion synthesis, the reaction byproduct, $\mathrm{MgO}$, was leached out from the synthesized powder by boiling in dilute $\mathrm{HCl}$ and the product was dried. The synthesized powder was characterized by X-ray diffraction (XRD) (Philips PW 1840, The Netherlands) and transmission electron microscopy (TEM) (JEOL, JEM 2010, Japan). The synthesized $\mathrm{ZrB}_{2}$ powder was used as reinforcing agent for the preparation of $\mathrm{ZrB}_{2}-\mathrm{Cu}$ composite.

The different amounts $(20,30,40,50,60,70 \mathrm{wt} \%)$ of $\mathrm{Cu}$ powder $(99.9 \%$ pure, Metal Powder Company, India) were dry mixed and compressed into $6.6 \mathrm{~mm}$ diameter and $5 \mathrm{~mm}$ thickness pellets by applying uniaxial pressure of $250 \mathrm{MPa}$. Pressureless sintering was carried out in a high temperature graphite furnace (Thermal Technology Inc, USA) at $1250^{\circ} \mathrm{C}$ under a continuous flow of pure argon gas (XL grade). Sintered density was measured with an accuracy of $\pm 1 \%$ by liquid immersion technique using Archimedes principle. Hardness (load at $300 \mathrm{~g}$ and loading time, $15 \mathrm{~s}$ ) of different sintered samples was measured by Vickers micro hardness tester (LECO DM400, Japan). The microstructures of sintered samples were studied by scanning electron microscope (SEM) (JEOL, JSM 840 A, Japan).

These sintered pellets were fixed on one end of a $\mathrm{Cu}$ (99.9\% pure) rod by adding a conductive Ag paste and this composite fixed with $\mathrm{Cu}$ rod was used as an electrode. It had been confirmed that there was very negligible current drop through this conductive paste. The well polished mild steel plate was used as WP material for EDM study. The EDM study was carried out by Charmilles (ELERODA 10, Switzerland). The tool and WP were kept as positive and negative electrodes, respectively. This type of polarity is used to get more wear of

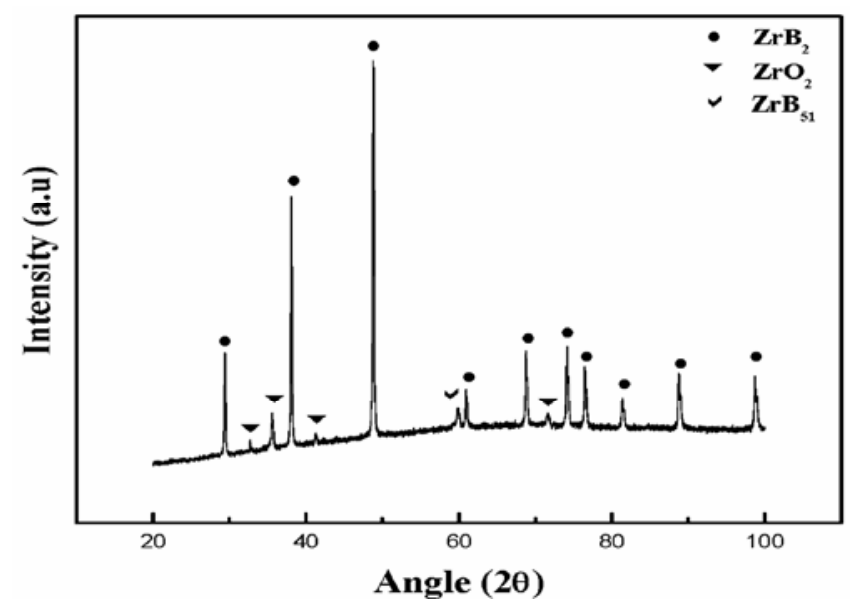

Figure 1. XRD pattern of synthesized powder.
WP than the tool material. The kerosene oil (fire point $\sim 65^{\circ} \mathrm{C}$ ) was used as dielectric fluid. The EDM study with different $\mathrm{ZrB}_{2}-\mathrm{Cu}$ composites were carried out at same operating condition (peak current, $3 \mathrm{Amp}$; gap voltage, $45 \mathrm{~V}$; pulse on-time, $30 \mu \mathrm{s}$ and duty factor, $95 \%$ ). A depth of cut of $0.2 \mathrm{~mm}$ was done on WP for each run. The MRR and TRR were measured for each run and were expressed by weight loss/min (mg/min). Here each run indicated that the experiment was repeated for same operating condition. Average surface roughness of machined WP and tool were also measured at different pulse on-time with the help of surface roughness measuring instrument [SURFCOM 120A, Carl Zeiss, Japan]. Diametric overcut of hole machined on WP was measured by tool maker microscope [Mitutoyo TM101, USA].

\section{Results and discussion}

The XRD pattern of synthesized powder shows presence of $\mathrm{ZrB}_{2}$ as a major phase with $\mathrm{ZrO}_{2}$ and $\mathrm{B}_{51} \mathrm{Zr}$ as minor phases (figure 1). The TEM image of synthesized powder is shown in figure 2. The image shows agglomeration of fine spherical particles and the average particles are found to be $\sim 50-75 \mathrm{~nm}$. The sintered density is found to increase with the $\mathrm{Cu}$ addition (figure 3). A maximum of $92 \%$ density is found at $70 \mathrm{wt} \% \mathrm{Cu}$ addition to $\mathrm{ZrB}_{2}$. The addition of more $\mathrm{Cu}$ to $\mathrm{ZrB}_{2}$ decreases the porosity of sintered samples, which is responsible for increase of sintered density with the addition of $\mathrm{Cu}$. It has been observed from XRD study of sintered samples that there is no interaction between $\mathrm{Cu}$ and $\mathrm{ZrB}_{2}$. Microhardness of sintered sample is found to increase with $\mathrm{Cu}$ addition and reaches a maximum value of $310 \mathrm{~kg} / \mathrm{mm}^{2}$ at $30 \mathrm{wt} \% \mathrm{Cu}$ and then decreases with $\mathrm{Cu}$ addition (figure 4). Maximum hardness at $30 \mathrm{wt} \% \mathrm{Cu}$ may be due to uniform distribu-

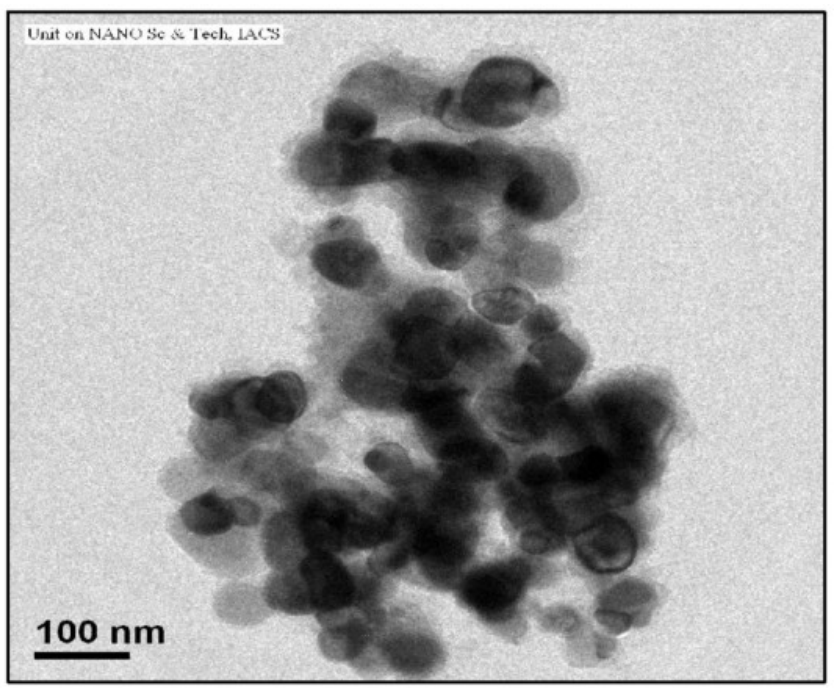

Figure 2. TEM image of synthesized powder. 
tion of $\mathrm{ZrB}_{2}$ particles in $\mathrm{Cu}$ matrix and beyond this level hardness decreases with the increase of $\mathrm{Cu}$ (soft phase) addition. The SEM images of sintered samples are shown in figure 5. It shows presence of agglomeration of fine $\mathrm{ZrB}_{2}$ particles in the $\mathrm{Cu}$ matrix.

The EDM studies with different composites as tool material are shown in figures 6-7. The MRR of different $\mathrm{ZrB}_{2}-\mathrm{Cu}$ composite tool is found to increase with $\mathrm{Cu}$ and reaches a maximum value at $40 \mathrm{wt} \% \mathrm{Cu}$ addition sample and later decreases (figure 6). The TRR increases with the increase of $\mathrm{Cu}$ (figure 7). Here we consider that the $\mathrm{ZrB}_{2}-40 \mathrm{wt} \% \mathrm{Cu}$ tool is the best performance tool because it shows highest MRR than others and TRR is lesser than 50, 60 and $70 \mathrm{wt} \% \mathrm{Cu}$ added sample. This $\mathrm{ZrB}_{2}-\mathrm{Cu}$ composite tool may have optimum combination of wear resistance, electrical and thermal conductivity. Hereafter, this $\mathrm{ZrB}_{2}-40 \mathrm{wt} \% \mathrm{Cu}$ tool will be referred to as A tool. Now the performance of this A tool is compared with the commonly used $\mathrm{Cu}$ tool.

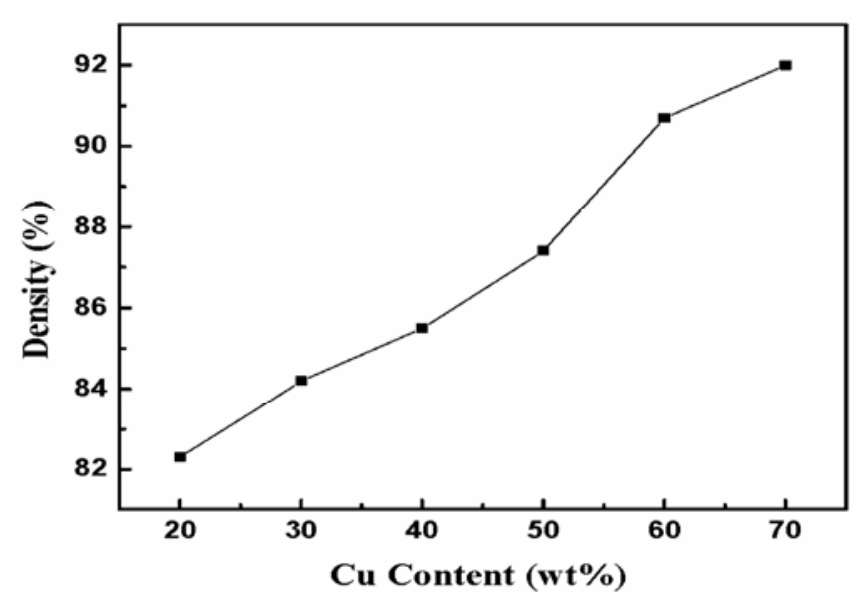

Figure 3. Relationship between sintered density and $\mathrm{Cu}$ content of different sintered samples.

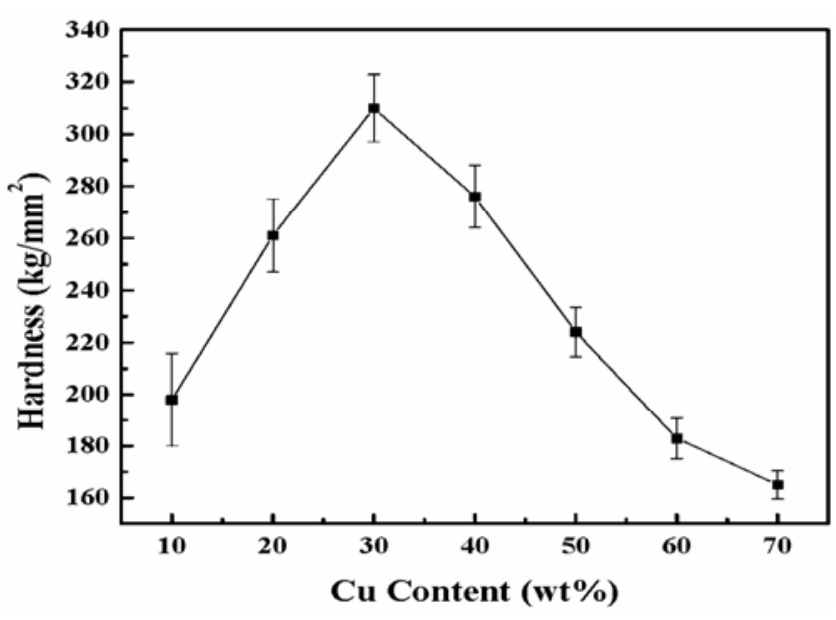

Figure 4. Microhardness of different sintered samples.
The MRR and TRR for both types of tools are shown in figure 8 . The MRR and TRR increase uniformly up to $30 \mu$ s pulse on-time and then increase rapidly. During EDM the positive ions liberated from tool surface will hit the WP surface and liberated electron from WP will hit the tool surface. Momentum of positive ion (from anode) is more than liberated electron from the cathode. This phenomenon leads to increase of more temperature on the WP surface as compared to tool, which finally results in more MRR on WP surface. Increase of more electrons with the pulse on-time lead to increase of TRR. The MRR for A tool is found to be higher than $\mathrm{Cu}$ tool and the TRR is also lesser in case of $\mathrm{A}$ tool than $\mathrm{Cu}$ tool. Presence of $\mathrm{ZrB}_{2}$ particle in $\mathrm{Cu}$ matrix increases the wear resistance of A tool, which leads to lesser TRR of A tool during EDM. The amount of worn out materials present between the WP and tool is lesser in case of A tool than $\mathrm{Cu}$ tool and these worn out materials act as resistance for uniform spark, which is more prone in case of $\mathrm{Cu}$ tool than A tool. This may result in higher MRR for A tool than $\mathrm{Cu}$ tool.

Figure 9 shows the average surface roughness of WP and tool after EDM. The average roughness is found to increase uniformly with the pulse on-time up to $20 \mu$ s and then increases rapidly from 20 to $30 \mu$ s pulse on-time and beyond $30 \mu$ s pulse on-time increased rapidly. This is due to more MRR due to more input of EDM energy and presence of residual debris on WP and tool surfaces. Average

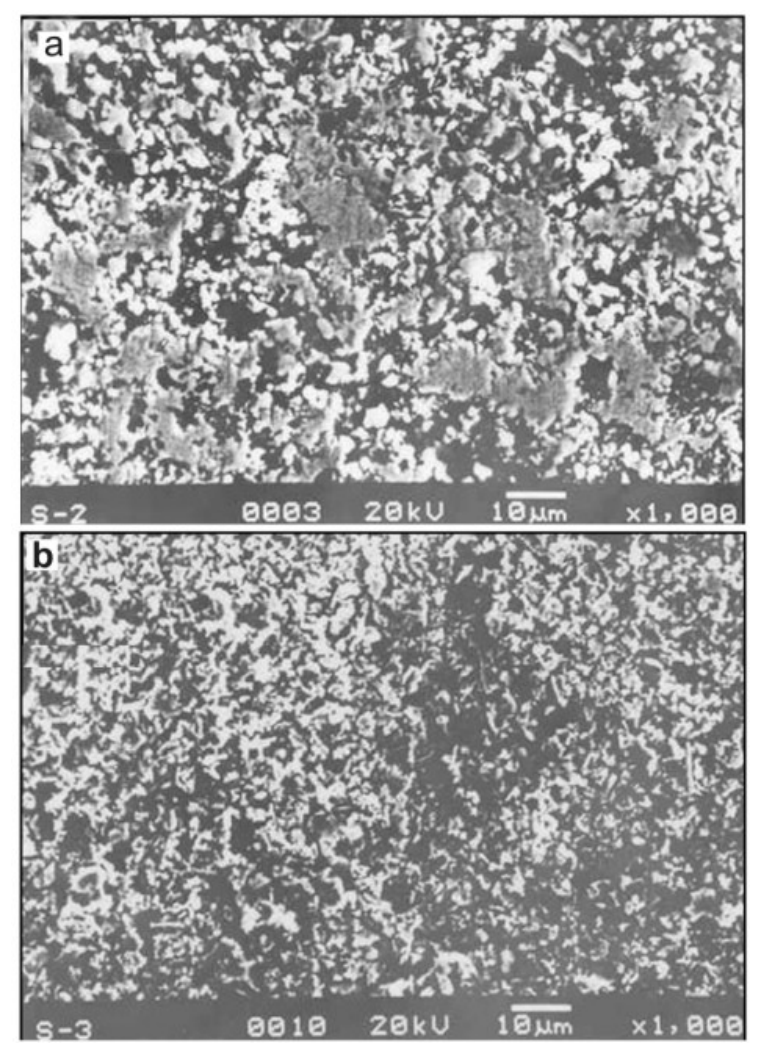

Figure 5. SEM images of different sintered samples. a. $20 \mathrm{wt} \% \mathrm{Cu}$ and b. $40 \mathrm{wt} \% \mathrm{Cu}$. 
surface roughness of WP and tool are more in case of A tool than $\mathrm{Cu}$ tool. Presence of $\mathrm{ZrB}_{2}$ particles as a dispersing agent in $\mathrm{Cu}$ matrix for $\mathrm{A}$ tool may result in increase of surface roughness than for $\mathrm{Cu}$ tool. A similar phenomenon is found in case of diameteral overcut of hole

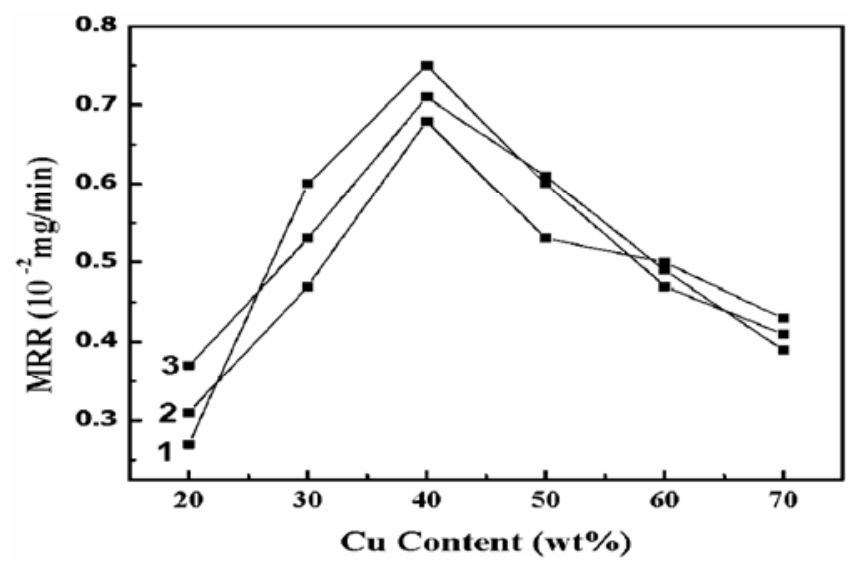

Figure 6. Variation of MRR with wt $\% \mathrm{Cu}$ tool at different runs $(1,2,3)$ (different runs indicate that the experiment was repeated for three times).

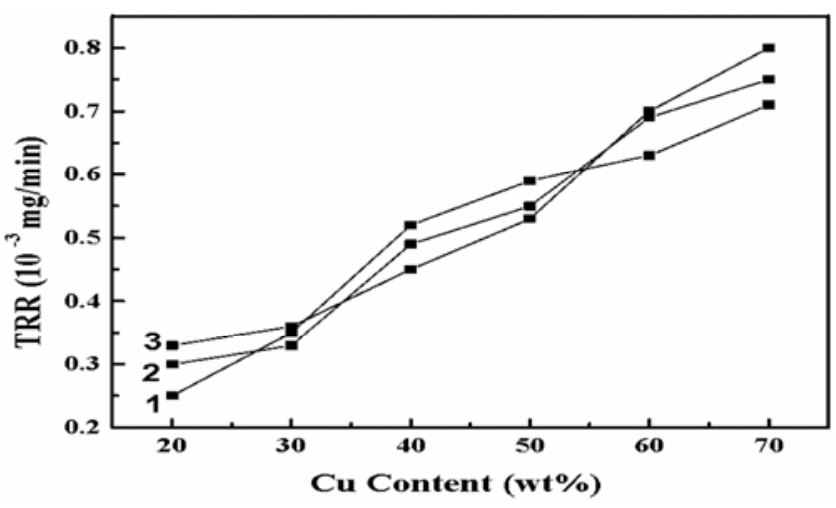

Figure 7. Variation of TRR with $\mathrm{wt} \% \mathrm{Cu}$ tool at different runs $(1,2,3)$.

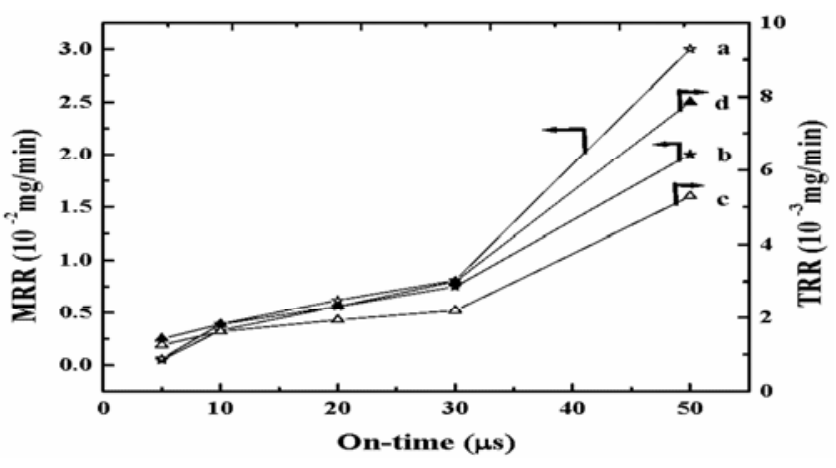

Figure 8. Variation of MRR and TRR with pulse on-time: a, b. are MRR for A tool and $\mathrm{Cu}$ tool and $\mathrm{c}, \mathrm{d}$. are TRR for A tool and $\mathrm{Cu}$ tool. machined on the WP (figure 10). As the input energy increases the electron bombardment from the side wall of tool increased, which led to more overcut in case of $\mathrm{A}$ tool than $\mathrm{Cu}$ tool. Presence of $\mathrm{ZrB}_{2}$ particles in the debris may also increase the diameteral overcut by rubbing action.

Higher roughness and diameteral overcut are undesirable phenomena for precision machining. This indicates that composite tool cannot be used for precision machining. Advantage of composite tool is high MRR with less TRR, which is an important factor for prolonged machining. This composite may be useful for rough machining, where precision is not much important.

\section{Conclusions}

Present investigation explores the preparation of ultrafine $\mathrm{ZrB}_{2}$ powder and development of $\mathrm{ZrB}_{2}-\mathrm{Cu}$ composites by pressureless sintering technique. The density, hardness and microstructure of sintered samples are studied. The sintered $\mathrm{ZrB}_{2}-\mathrm{Cu}$ composites have been tested as EDM cutting tool material.

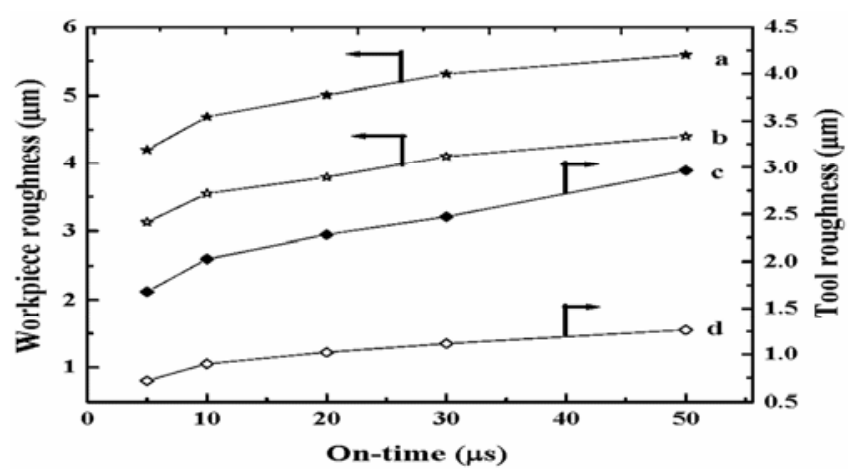

Figure 9. Variation of average surface roughness with pulse on-time: $\mathrm{a}, \mathrm{b}$. are $\mathrm{WP}$ roughness for $\mathrm{A}$ tool and $\mathrm{Cu}$ tool and $\mathrm{c}, \mathrm{d}$. are tool roughness of $\mathrm{A}$ tool and $\mathrm{Cu}$ tool.

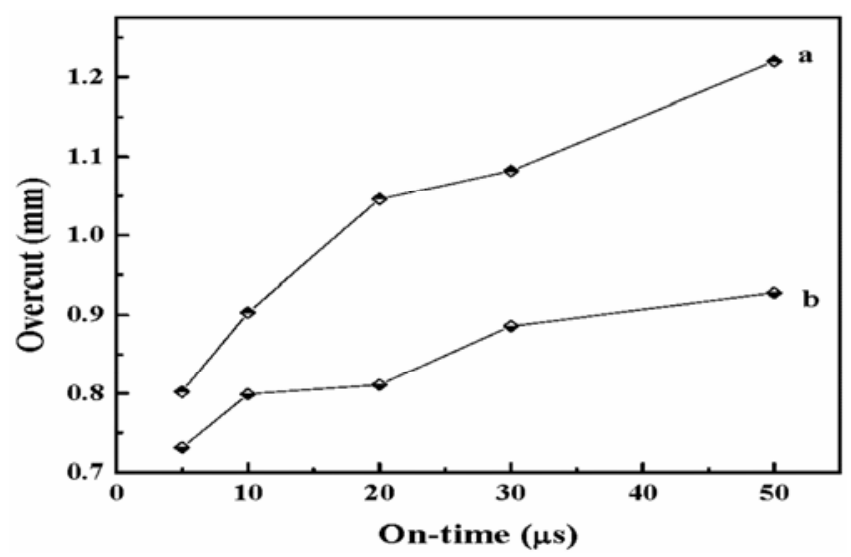

Figure 10. Variation of diameteral overcut with different pulse on-time: a. A tool and b. $\mathrm{Cu}$ tool. 
The higher metal removal rate is found at $40 \mathrm{wt} \% \mathrm{Cu}$ addition to $\mathrm{ZrB}_{2}$ sample as compared to other composition. The $\mathrm{ZrB}_{2}-40 \mathrm{wt} \% \mathrm{Cu}$ composite also shows more metal removal rate with lesser tool removal rate than conventional $\mathrm{Cu}$ tool. Average surface roughness and diameteral overcut are found to be more in case of composite tool than $\mathrm{Cu}$ tool.

\section{References}

Gadalla A M, Bozkurt B and Faulk N M 1991 J. Am. Ceram. Soc. 74801

Ho K H and Newman S T 2003 J. Mater. Proc. Technol. 431287
Khanra A K and Khanra A 2005 J. Mater. Sci. 403027

Khanra A K, Patra S and Godkhindi M M 2006 Bull. Mater. Sci. 29227

Marafona J and Wykes C 2000 Int. J. Mach. Tools Manuf. 40 153

Norasetthekul S, Eubank P T, Bradley W L, Bozkurt B and Stucker S 1999 J. Mater. Sci. 341261

Petrofes N F and Gadalla A M 1988 Ceram. Bull. 671048

Samuel M P and Philip P K 1997 Int. J. Mach. Tools Manuf. 37 1625

Singh S, Maheshwari S and Pandey P C 2004 J. Mater. Proc. Technol. 149272

Tsai H C, Yan B H and Huang F Y 2003 Int. J. Mach. Tools Manuf. 43245 